\title{
Rancang Bangun Sistem Informasi Manajemen Konferensi Ilmiah Berbasis Web
}

\author{
I Nyoman Darma Kotama, Made Sudarma ${ }^{\star}$ I Made Arsa Suyadnya \\ Program Studi Teknik Elektro, Fakultas Teknik, Universitas Udayana \\ Email: msudarma@unud.ac.id ${ }^{*}$
}

\begin{abstract}
ABSTRAK
Pada penelitian ini dibangun sebuah sistem website dengan framework PHP Laravel 5.2 dan DBMS MySQL dengan berisikan 6 buah modul kebutuhan pengelolaan konferensi ilmiah yaitu Master Konferensi, User Management, Submission, Manajemen Website, Schedule, dan Post Conference. Dari proses pengerjaan dan pengujian sistem dengan metode Black Box disimpulkan bahwa sistem berjalan baik dan layak untuk diterapkan untuk pengelolaan konferensi di Program Studi Teknik Elektro Fakultas Teknik Universitas Udayana.
\end{abstract}

Kata Kunci: Konferensi IImiah, Sistem Informasi, Sistem Informasi Konferensi IImiah

This paper is projecting website system built on top of PHP Framework Laravel 5.2 and MySQL DBMS which contains 6 modules of scientific conference management needs, Master Conference, User Management, Submission, Website Management, Schedule, and Post Conference. From the development and testing system with Black Box method concluded that the system is running well and feasible to be applied to the management of the conference in Electrical Engineering Program Faculty of Engineering Udayana University.

Keywords: Scientific Conference, Information System, Scientific Conference Management System

\section{PENDAHULUAN}

Konferensi IImiah merupakan sebuah ruang sosial untuk para akademisi untuk menyajikan, belajar, dan mendiskusikan penelitian yang sedang mereka lakukan. Pada umumnya konferensi ilmiah melibatkan berbagai interaksi diantara peserta yang dibagi menjadi dua kategori. Kategori formal yaitu presentasi hasil penelitian, research papers dan posters kemudian kategori informal meliputi pertukaran informasi antara masing-masing peserta saat jam istirahat[1].

Manajemen Konferensi adalah sebuah konsep merencanakan dan mengelola sebuah kegiatan konferensi dari sebelum konferensi dimulai (pre-conference) hingga setelah konferensi dimulai (post conference)[2]. Proses dan kegiatan pengelolaan ini meliputi empat kebutuhan dasar yaitu, pengumpulan papers, review papers, penetapan papers dan proceeding/camera-ready paper collection [3].

Program Studi Teknik Elektro dan Komputer, Fakultas Teknik, Universitas Udayana merupakan sebuah lembaga akademik yang sering kali melakukan kegiatan konferensi ilmiah, baik skala nasional maupun internasional. Untuk memenuhi kebutuhan pengelolaan manajemen konferensi karya ilmiah di program studi teknik elektro, akan dibuat sebuah sistem yang mengacu pada empat kebutuhan dasar konferensi beserta tiga buah modul baru yaitu Manajemen Pengguna, Manajemen Antarmuka Website, dan Pembayaran Pendaftaran Konferensi.

\section{KAJIAN PUSTAKA}

\subsection{Sistem Informasi}

Sistem Informasi terdiri dari dua kata, yaitu sistem dan informasi. Sistem dalam bahasa yunani adalah systema, yang mempunyai pengertian sehimpunan bagian atau komponen yang saling berhubungan secara teratur dan merupakan suatu kesatuan yang tidak terpisahkan, sedangkan informasi merupakan kumpulan dari beberapa data. Menurut para ahli sistem informasi adalah suatu kegiatan dari prosedur-prosedur yang diorganisasikan, bilamana dieksekusi akan menyediakan 
informasi untuk mendukung pengambilan keputusan dan pengendalian dalam suatu organisasi [4].

\subsection{Metode Pengembangan Sistem Informasi}

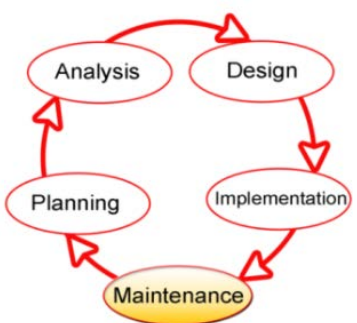

Gambar 1 Alur System Development Life Cycle

Pada gambar 1 dapat dilihat alur SDLC juga di sebut sebagai Application Development Life-Cycle sebuah alur konsep yang digunakan untuk pengembangan sebuah sistem perangkat lunak yang meliputi proses Planning (perencanaan), Creating (pembuatan), Testing (pengujian) dan Implementation (penerapan)[5].

\subsection{Pemodelan Sistem}

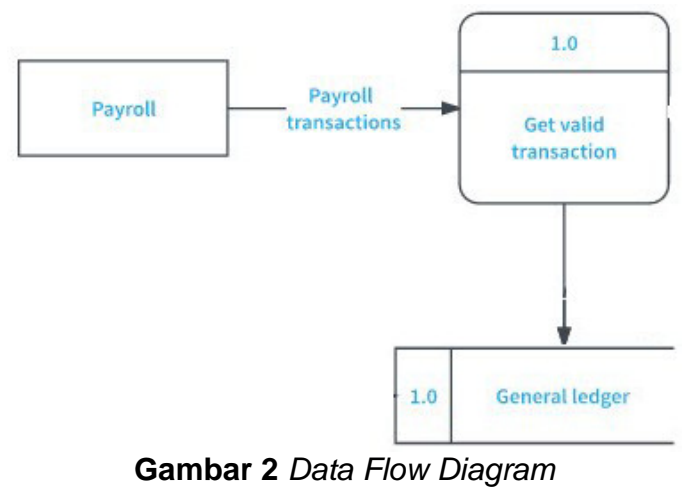

Pada Gambar 2 dapat dilihat contoh sederhada bagaimana Diagram Aliran Data (DFD) bekerja. DFD adalah representasi grafis dari flow atau arus Sistem Informasi Manajemen. Aliran diagram juga bisa digunakan untuk visualisasi Data Pengolahan. DFD menunjukkan interaksi antara sistem dan entitas luar [6].

\subsection{Basis Data}

Secara umum sistem basis data dapat didefinisikan sebagai koleksi dari data yang teroganisir sedemikian rupa sehingga data mudah disimpan dan dimanipulasi. Manipulasi yang dimaksud yaitu diperbarui, dicari, diolah dengan perhitunganperhitungan tertentu, serta dihapus. Salah satu tujuan sistem basis data adalah menyediakan pengguna suatu pandangan abstrak dari data, yaitu sistem yang menyembunyikan rincian mengenai bagaimana data disimpan dan dipelihara, Agar sistem bermanfaat, pengguna sistem seharusnya dapat memanggil data secara efiesien[7].

\subsection{Framework PHP Laravel}

Laravel adalah sebuah framework PHP yang dapat digunakan secara bebas. Laravel mampu mengubah proses pengembangan sistem menjadi menyenangkan dan mudah. Laravel menyediakan kode sintaks yang ekpresif dan mengesankan, memungkinkan sebuah aplikasi yang cepat, stabil dan mudah untuk dipelihara serta dikembangkan [8].

Dalam pengelolaan alur sistemnya Laravel memanfaatkan Konsep MVC. Konsep MVC memecah logika program menjadi tiga buah bagian Model-ViewController (MVC). Alur operasi dari MVC dapat dibagi menjadi 6 tahap, yaitu[9]:

1. Pengguna mengirimkan request ke Controller

2. Controller menganalisa request dan memanggil model lewat method di class nya

3. Model akan melakukan logika yang sudah diprogram dengan database

4. Model lalu menyampaikan hasilnya ke Controller

5. Controller lalu melanjutkan hasilnya ke View

6. Permintaan kemudian disampaikan ke pengguna lewat View

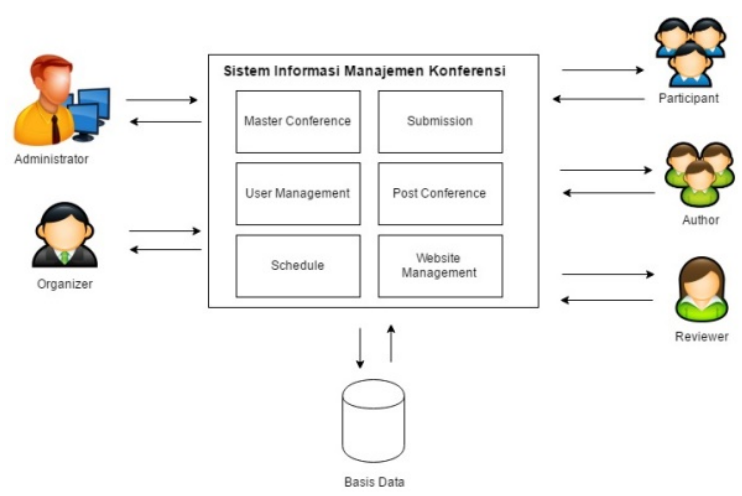

Gambar 3 Gambaran Umum Aplikasi 


\section{METODE PENELITIAN}

\subsection{Gambaran Umum Sistem}

Pada Gambar 3 disajikan sebuah diagram beberapa modul yang akan diimplementasikan dalam sistem. Hanya akan ada 1 grup pengguna yang b. Mampu mengubah info website konferensi yang terdaftar di sistem.

c. Mampu mendaftarkan pengguna baru, mengubah data pengguna yang sudah terdaftar, menghapus pengguna, dan memberikan hak akses ke pada

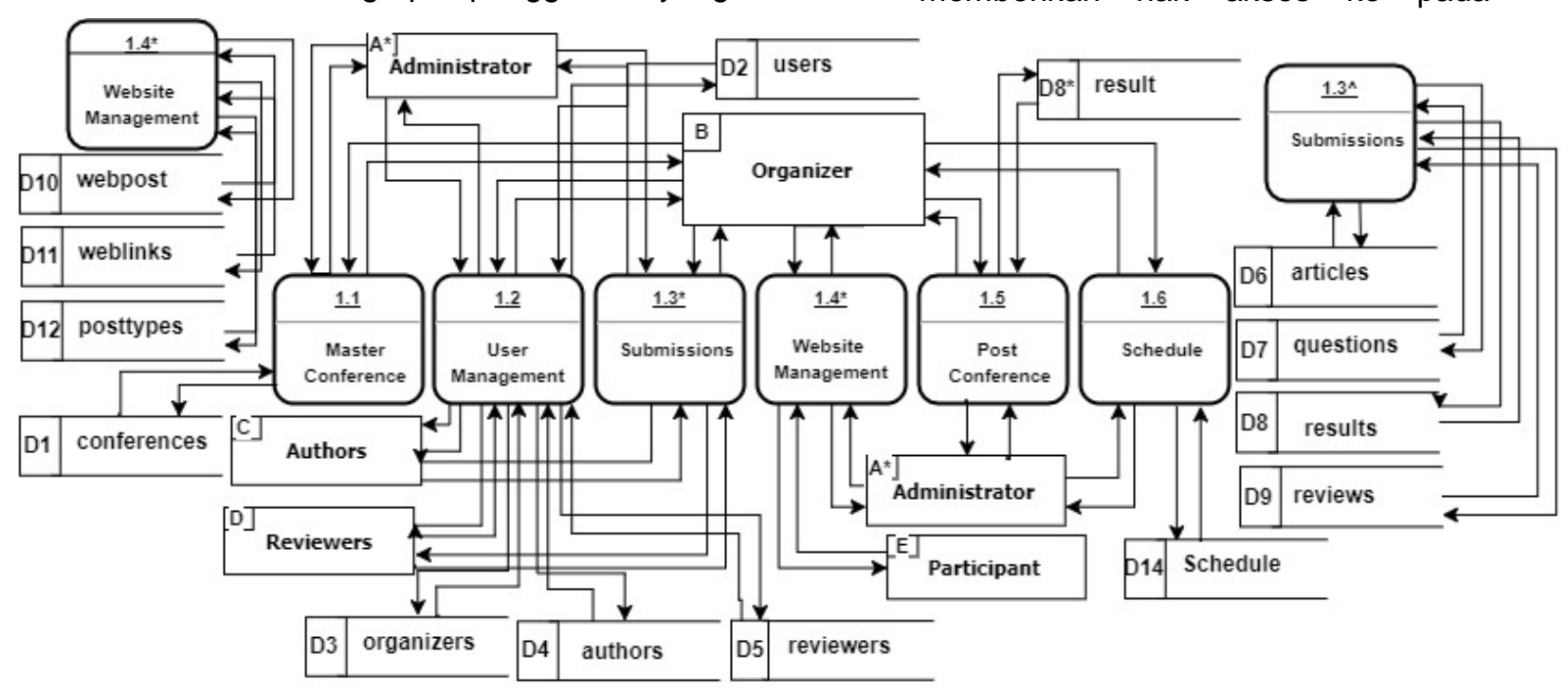

Gambar 4 Data Flow Diagram Level 0

diperbolehkan untuk mengelola sistem, grup yang pertama, yaitu Administrator.

Administrator memiliki hak penuh pada setiap pengambilan keputusan sistem, dari hak yang paling tinggi yaitu membuat sebuah konferensi baru lewat modul Master Conference hingga mengatur siapa saja yang diperbolehkan untuk masuk dalam tim panitia pada masing-masing konferensi.

Yang kedua adalah Organizer atau panitia, tim panitia dibentuk oleh Administrator lewat modul Management User. Organizer memiliki hak akses sedikit di bawah Administrator yaitu mengelola konten dan keberlangsungan konferensi yang sudah dibuat oleh Administrator.

\subsection{Analisis Kebutuhan Fungsional Sistem}

1. Administrator

Administrator bisa mengelola sistem secara keseluruhan dari per satu konferensi hingga semua konferensi. Adapun kebutuhan pengguna dengan hak akses Administrator adalah,

a. Mampu membuat konferensi baru, mengubah konferensi yang sudah ada, dan menghapus konferensi. pengguna sebagai Author, Organizer ataupun Reviewer.

2. Organizer

Organizer memiliki akses pengelolaan per konferensi. Hal ini untuk memperjelas penugasan per konferensi.

a. Mampu mengubah data konferensi yang ditugaskan.

b. Mampu mengubah info website konferensi yang ditugaskan.

c. Mampu mendaftarkan pengguna baru, mengubah data pengguna yang sudah terdaftar, menghapus pengguna, dan memberikan hak akses ke pada pengguna sebagai Author, Organizer ataupun Reviewer pada konferensi yang ditugaskan.

\section{Reviewer}

Reviewer adalah grup pengguna yang bertugas untuk memberikan hasil review atau saran layak atau tidaknya sebuah artikel untuk masuk ke dalam sebuah konferensi. Dengan demikian reviewer harus mampu melakukan proses review paper.

\section{Author}

Author atau penulis artikel, adalah seseorang yang akan atau sudah terdaftar ke dalam sistem. Author secara fungsional 
harus mampu untuk melakukan beberapa hal, yaitu:

a. Melakukan registrasi, dan bergabung pada salah satu konferensi terdaftar di sistem.

b. Melakukan proses upload paper, upload camera ready, dan verifikasi pembayaran

\subsection{Pemodelan Sistem}

Proses pemodelan sistem dilakukan dengan mengolah kebutuhan sistem menjadi sebuah gambaran alir kerja sistem. Gambar 4 merupakan alir kerja sistem berupa Data Flow Diagram Level 0. seluruh data konferensi, Tabel Users untuk menyimpan seluruh data pengguna terdaftar, Tabel Authors, Organizers, Reviewers untuk menyimpan keterangan grup pengguna, Tabel Schedule untuk menyimpan data waktu konferensi, Tabel Articles, Questions, Results, Finalpapers, dan Reviews untuk data yang dibutuhkan oleh proses review artikel, dan Tabel Webpost, Weblinks, Posttypes untuk menyimpan data tampilan website.

\section{HASIL DAN PEMBAHASAN}

4.1 Hasil

Hasil dari penelitian ini adalah sebuah

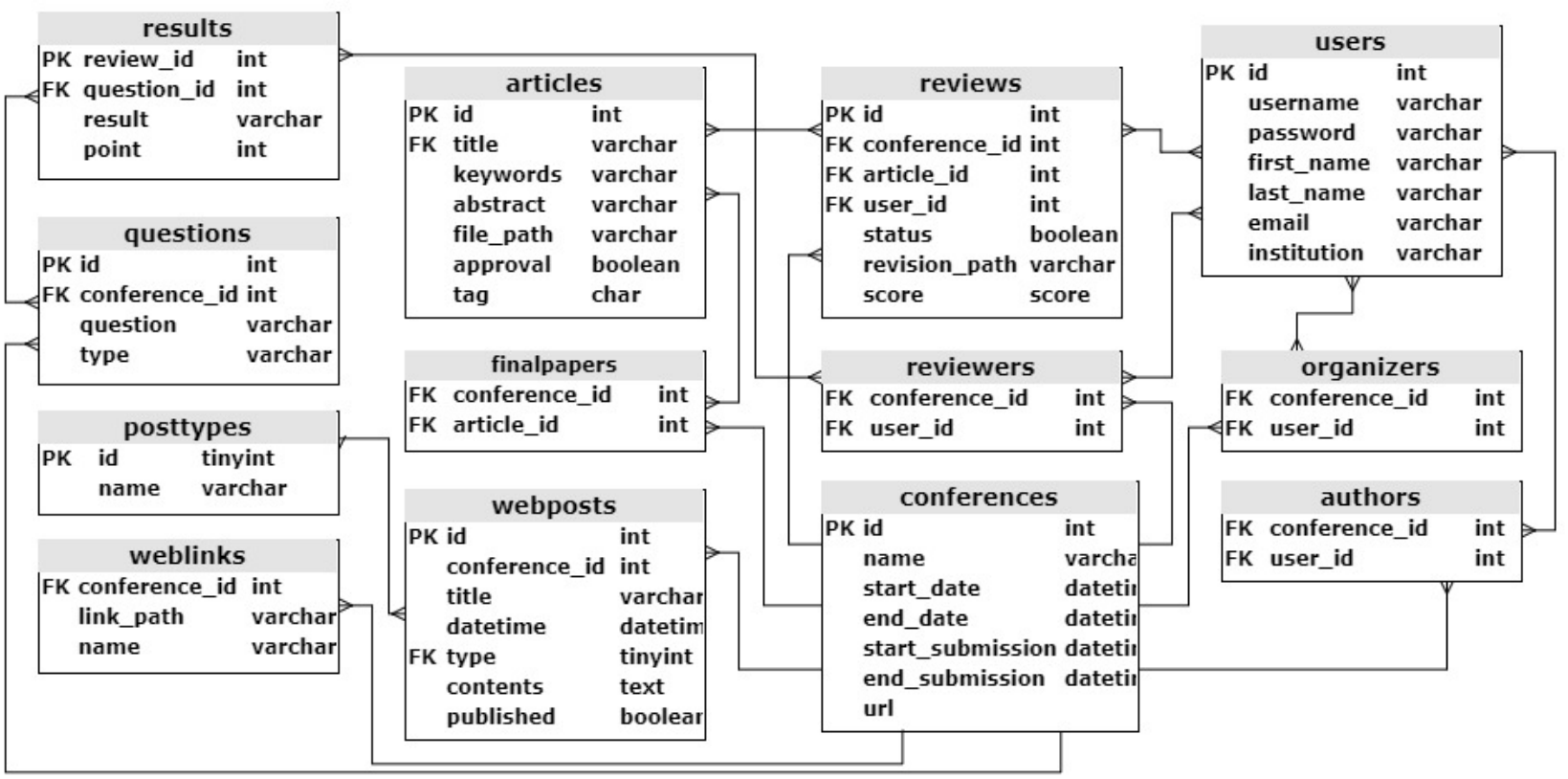

Gambar 5 Physical Database Model

Diagram alir pada Gambar 4 melibatkan 6 buah modul; yaitu Modul Master Conference, Modul User Management, Modul Submission, Modul Website Management, Post Conference, dan Modul Schedule.

Entitas atau pengguna yang terlibat sesuai dengan kebutuhan fungsional sistem, yaitu; Administrator, Organizer, Reviewer, dan Author.

\subsection{Perancangan Database}

Rancangan Database dilakukan dengan penggambaran Physical Database Model (PDM) yang ditunjukkan pada Gambar 5. Physical Database Model menyajikan 14 buah bentuk tabel yaitu; Tabel Conferences untuk menyimpan aplikasi yang dapat digunakan untuk melakukan Manajemen Konferensi IImiah Berbasis Web. Aplikasi ini dibangun dengan Framework PHP Laravel 5.2 dengan DBMS MySQL.

\subsection{Pembahasan}

Pembahasan aplikasi akan mencakup hasil dari pengembangan yang sudah dilakukan dengan menjabarkan kegunaan masing-masing modul dan tampilannya. 


\section{All Conferences Add Conference}

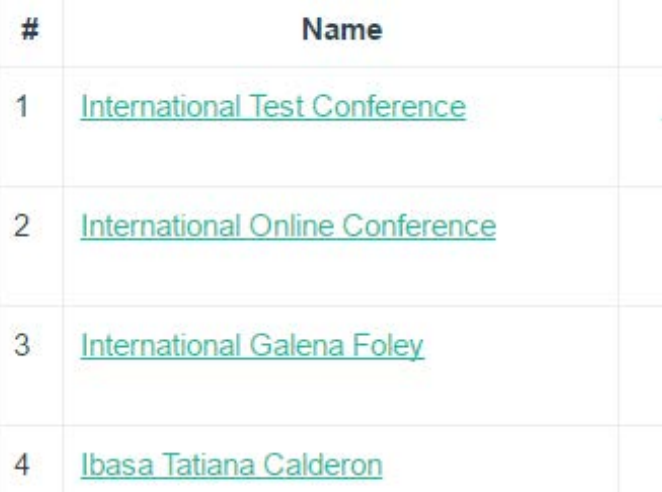

Gambar 6 Modul Master Konferensi

\subsubsection{Modul Master Conference}

Gambar 6 merupakan tampilan Modul Master Conference. Modul ini merupakan modul yang digunakan untuk mengelola master data yang terkait dalam sistem. Modul ini hanya dapat diakses oleh pengguna yang memiliki hak akses administrator dan organizer.

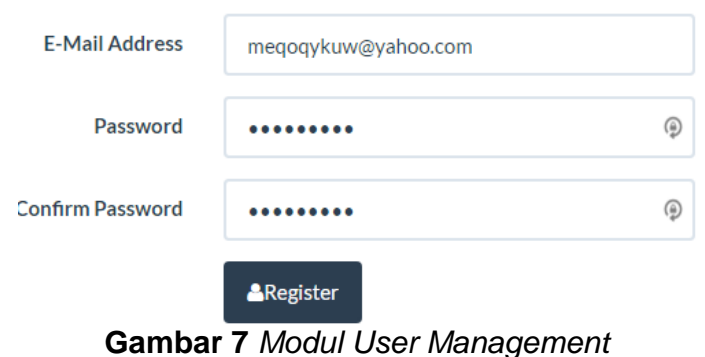

\subsubsection{Modul User Management}

Gambar 7 merupakan tampilan Modul User Management yang dapat diakses oleh pengguna yang belum terdaftar untuk mendaftarkan diri. Dalam pengelolaan sistem, pengguna yang memiliki hak akses Administrator \& Organizer dapat mengakses modul ini untuk mengelola hak akses pengguna.

Modul User Management adalah modul yang bertanggung jawab untuk mengelola bagaimana pengguna dapat menggunakan sistem. Penggunaan tersebut meliputi pemberian hak akses Administrator, Organizer, Author, dan Reviewer.

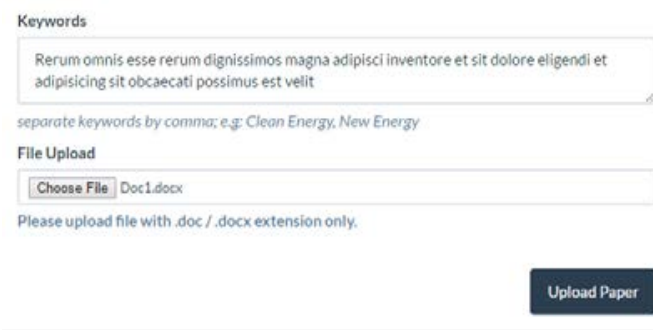

Gambar 8 Modul Submission

\subsubsection{Modul Submission}

Gambar 8 adalah tampilan Modul Submission adalah modul yang dapat diakses oleh semua pengguna yang terdaftar di sistem, yaitu Author, Reviewer, dan Organizer. Modul Submissions adalah modul utama dalam sistem manajemen

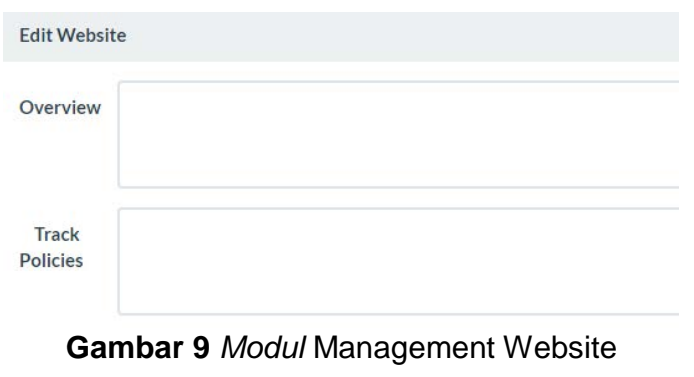

\subsubsection{Modul Manajemen Website}

Gambar 9 merupakan tampilan Modul Manajemen Website yang berfungsi untuk mengelola tampilan halaman depan website. Untuk mengakses modul ini pengguna harus memiliki hak akses Organizer.

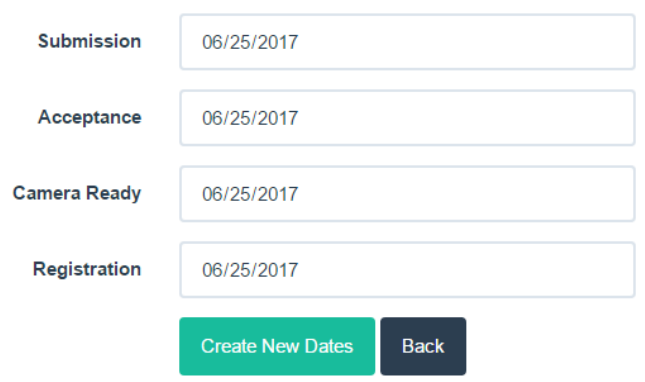

Gambar 10 Modul Schedule

\subsubsection{Modul Schedule}


Gambar 10 merupakan tampilan Modul Schedule yang berguna untuk menentukan batas-batas waktu penting dalam konferensi. Batasan waktu diberikan agar konferensi berjalan sesuai jadwal. Selain menentukan batas waktu, modul ini juga memungkinkan pengelola sistem untuk memperpanjang batasan waktu yang sudah dibuat sehingga konferensi menjadi lebih fleksibel.

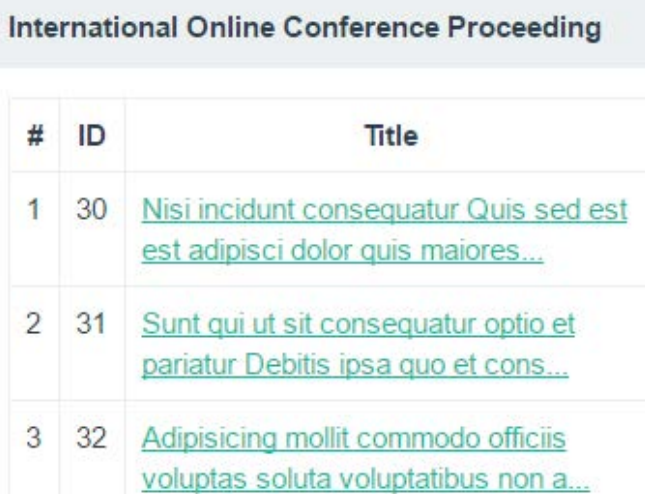

Gambar 11 Modul Post Conference

\subsubsection{Modul Post Conference}

Gambar 11 adalah tampilan Post Conference. Modul ini bertugas untuk menangani paper yang sudah berstatus "Registered" atau paper yang statusnya sudah diterima untuk di presentasikan di konferensi. Paper tersebut di sajikan dalam bentuk data proceeding.

\subsection{Pengujian}

Pengujian aplikasi dengan metode Blackbox bertujuan untuk mengetahui kelayakan aplikasi dalam memproses masukan dan keluaran pengguna. Pengujian dilakukan sebanyak modul yang ada, yaitu sebanyak 6 buah modul. Hasil pengujian menyatakan keseluruhan fungsi aplikasi sudah berjalan dengan baik.

\section{KESIMPULAN}

Dari proses penelitian perangkat lunak yang telah dilakukan, meliputi proses perencanaan, pembuatan dan pengujian system, disimpulkan perangkat lunak telah mampu menangani 4 kebutuhan dasar pengelolaan konferensi ilmiah. Berdasarkan proses pengujian perangkat lunak dengan metode Blackbox, keseluruhan fungsionalitas aplikasi telah berjalan dengan baik.

Pengembangan Sistem Manajemen Konferensi Ilmiah Berbasis Web ini selanjutnya dapat ditambahkan fitur peringatan kepada Organizer ketika memasuki masa deadline atau batas akhir pengumpulan review.

\section{DAFTAR PUSTAKA}

[1] J. Mccarthy, D. W. McDonald, S. Soroczak, D. Nguyen, and A. Rashid, "Augmenting the social space of an academic conference," CSCW 04 Proc. 2004 ACM Conf. Comput. Support. Coop. Work, pp. 39-48, Jan. 2004.

[2] B. Subramaniam, "WEBCON AN ONTOLOGY ENGINE BASED CONFERENCE ORGANISER," Thesis, 2008.

[3] L. Padgham, J. Thangarajah, and M. Winikoff, "The Prometheus Design Tool-A Conference Management System Case Study," Lect. Notes Comput. Sci., vol. 4951, pp. 197-211, 2008.

[4] H. C. Lucas Jr, "Empirical evidence for a descriptive model of implementation," MIs Q., pp. 27-42, 1978.

[5] Departement Of Health \& Human Services USA, "Selecting Development Approach," Departement Of Health \& Human Services USA, 2008.

[6] N. Khot, K. Mudur, O. Thorat, and Y. Doulatramani, "Campus Cloud-A Management Information System on Cloud," 2017.

[7] A. Nugroho, "Perancangan dan Implementasi sistem basis data," Yogyak. Andi, 2011.

[8] M. Surguy, Laravel: My First Framework. Chapter, 2014.

[9] C. Supaartagorn, "PHP Framework for database management based on MVC pattern," Int. J. Comput. Sci. Inf. Technol. IJCSIT, vol. 3, no. 2, pp. 251258, 2011. 